\title{
Deionized water as vase solution prolongs flower bud opening and vase life in carnation and rose through sustaining an improved water balance
}

\author{
M. Ahmadi-Majd ${ }^{1}$, A. Rezaei Nejad ${ }^{1}$, S. Mousavi-Fard ${ }^{1}$ and D. Fanourakis ${ }^{2}$ \\ ${ }^{1}$ Department of Horticultural Sciences, Faculty of Agriculture, Lorestan University, Khorramabad, Iran \\ ${ }^{2}$ Laboratory of Quality and Safety of Agricultural Products, Landscape and Environment, Department of Agriculture, School \\ of Agricultural Sciences, Hellenic Mediterranean University, Estavromenos, Heraklion, Greece
}

\begin{abstract}
Summary
Vase life experiments are performed by employing mostly deionized water, and secondarily tap water. However, it has been suggested that the former reduces the cut chrysanthemum vase life, while the quality of the latter depends on the location and the season. To counteract these offsets, the Van Meeteren solution (deionized water containing $\mathrm{CuSO}_{4}, \mathrm{CaCl}_{2}$ and $\mathrm{NaHCO}_{3}$ at low concentrations) has been alternatively proposed as vase solution. In this study, we addressed the effect of these three alternatives on vase life and flower bud opening of cut carnation and rose (three cultivars each). In both species, deionized water as vase solution resulted in the longest vase life and most complete flower bud opening, while tap water led to the shortest vase life and the least complete flower opening. Deionized water also promoted both the rehydration ability and vase life in cut roses that were mildly desiccated (up to $85 \%$ of initial weight) prior to evaluation. These effects were related to improved water balance throughout vase life, owing to enhanced water uptake. Blocking microbial growth did not affect the noted differences among the three holding solution alternatives. By employing cut carnation and rose in combination with several postharvest scenarios, we conclude that deionized water as vase solution prolongs vase life and sustains flower bud opening owing to improved water relations.
\end{abstract}

Keywords

holding solution, keeping quality, tap water,

Van Meeteren solution, vase water, water relations

\section{Abbreviations}

FW, fresh weight; RH, relative air humidity; VPD, vapor pressure deficit; 8-HQS, 8-hydroxyquinoline sulfate.

\section{Introduction}

The vase life of cut flowers is the period between the placement of stems in a vase solution and the loss of ornamental value. It is an important parameter, which is considered for (a) the selection of genotypes in breeding programs, (b) the determination of storage and distribution conditions' effects, as well as (c) the design of optimal packaging and chemical treatment solutions (Fanourakis et al., 2013;

\section{Significance of this study}

What is already known on this subject?

- In postharvest studies, three types of vase solution (tap water, deionized water, Van Meeteren solution) are utilized.

What are the new findings?

- Vase life and flower opening were promoted by using deionized water, whereas these were limited by tap water. This effect was noted in both fully-hydrated and partly-desiccated cut flowers, and was related to improved water uptake.

What is the expected impact on horticulture?

- Deionized water as either hydration medium or holding solution appears superior, as compared to the other two types of vase solution.

Carvalho et al., 2015; Pouri et al., 2017; Onozaki, 2018).

To facilitate comparisons between studies, conditions during vase life evaluation have been agreed in the Second International Symposium on Postharvest Physiology of Cut Flowers (Reid and Kofranek, 1980), including the use of deionized/distilled water (i.e., water without minerals, $\mathrm{pH}$ of about 5.8) as holding solution. Deionized water was chosen in place of tap water, since the mineral composition, mineral content and $\mathrm{pH}$ of the latter vary depending on both the location and the season (Xie et al., 2008). Despite advice against its use, tap water has been employed as holding solution in roughly one third of the vase life studies (Fanourakis et al., 2015).

Two decades after the commonly agreed protocol for vase life evaluation, the use of deionized water as holding solution has been challenged (Van Meeteren et al., 1999). In that study it was highlighted that deionized water is not only uncommon at the consumer level, where tap water is regularly used as vase solution, but also in planta, where xylem sap contains minerals. Since, as earlier discussed, tap water should not be employed as holding solution in scientific studies, Van Meeteren et al. (1999) proposed the use of an artificial tap water (i.e., deionized water containing $\mathrm{CuSO}_{4}$, $\mathrm{CaCl}_{2}$ and $\mathrm{NaHCO}_{3}$ at low concentrations; further referred as Van Meeteren solution) as vase solution. It was also shown that deionized water decreased the cut chrysanthemum vase life, as compared to cut flowers placed in either the proposed vase solution or tap water. 
In a recent review, Van Doorn (2012) questioned the use of Van Meeteren solution as vase solution in vase life studies, and provided arguments in favor of deionized water. He discussed that the positive effect of Van Meeteren solution on cut chrysanthemum vase life is related to the dual action of $\mathrm{Cu}^{2+}$ on suppressing both microbial growth and the wound-induced xylem blockage, with the latter being noted in specific species (chrysanthemum, Astilbe and Bouvardia). Since only specific species undergo the wound-induced $\mathrm{xy}$ lem blockage, the Van Meeteren solution may be of limited value in the remaining cut flowers, and thus deionized water should remain as vase solution in keeping quality experiments (Van Doorn, 2012).

The present study investigates the effect of different types of vase solution (tap water, deionized water, and Van Meeteren solution) on postharvest water relations, cut flower longevity and flower bud opening of carnation and rose. We further analyzed whether the noted differences between treatments could be attributed to variation in microbial growth. In complementary experiments, it was hypothesized that the type of vase solution also affects the rehydration capacity, and through this the vase life of cut flowers that were previously partly desiccated (as takes place in dry-storage; Fanourakis et al., 2016b).

\section{Materials and methods}

\section{Plant material and growth conditions}

Cut carnation and rose flowers were obtained from two commercial growers, respectively. In both cases, plants were grown in a multispan plastic greenhouse, located in the central-west part of Iran [rose: Khorramabad $\left(33.5^{\circ} \mathrm{N}\right)$, carnation: Mahalat $\left.\left(33.9^{\circ} \mathrm{N}\right)\right]$. Two harvests were conducted $(6$ and 20 September, 2018), supplying material for the two respective experiments. In the first harvest, three cultivars per species (cut carnation: 'White Liberty', 'Grand Slam', 'Kirsi'; cut rose: 'Samurai', 'Avalanche', 'Sorbet') were tested. In the second experiment, a single cut rose cultivar ('Avalanche') was employed.

Twenty days prior to each harvest (corresponding to the growth period), climate parameters were automatically registered (every $10 \mathrm{~min}$ ) in both greenhouses, where cut flowers were obtained. These were recorded by sensors, which were installed in the upper third of the plant canopy. Preceding the first harvest, mean air temperature was $22.3 \pm$ $0.4^{\circ} \mathrm{C}$ (cut carnation) and $23.1 \pm 0.4^{\circ} \mathrm{C}$ (cut rose), respectively, while prior to the second harvest it was $23.3 \pm 0.4^{\circ} \mathrm{C}$ (cut rose). Relative air humidity (RH) averaged $66 \pm 4 \%$ in either greenhouse during both periods, resulting in a vapor pressure deficit (VPD) range of 0.79 to $1.11 \mathrm{kPa}$ across the two experiments. The average daily light integral was $10.3 \pm 0.1 \mathrm{~mol}$ $\mathrm{m}^{-2}$ day $^{-1}$ (LI-250A, LI-COR, Lincoln, NE). No artificial illumination was employed during cultivation. High RH ( $\geq 85 \%$ ) and irregular light patterns (e.g., continuous light; Sørensen et al., 2020), were thus avoided during plant growth, which would decrease vase life owing to reduced stomatal sensitivity to closing signals (reviewed by Fanourakis et al., 2016a, 2020a).

In cut carnation, approximately $50 \mathrm{~cm}$ long shoots were sampled upon outer petals were just horizontal. In either experiment, harvested cut rose shoots had a length of approximately $60 \mathrm{~cm}$ and a flower bud with a cylindrical shape and pointed tip. Replicate shoots were collected from different plants of similar stature. Cut flowers were collected in the morning (08:00-10:00 am; Fanourakis et al., 2013), and immediately placed in clean buckets filled with fresh water at a height of $15 \mathrm{~cm}$. The stems were transferred to the laboratory in these buckets at the day of harvest and by using refrigerated transport $\left(2^{\circ} \mathrm{C}\right)$. Upon arrival, both stem length and number of leaves were normalized (Fanourakis et al., 2013). Stems were re-cut under water (to prevent air entrance into the xylem conduits that were exposed by cutting) to a total length of 40 and $45 \mathrm{~cm}$ for cut carnation and rose, respectively. Six and three leaves were left on the stem for cut carnation and rose, respectively, while the remaining ones on the lower part of the shoot were stripped. Cut flowers were stored overnight in clean buckets (filled with fresh water at a height of $15 \mathrm{~cm}$ ), at $2^{\circ} \mathrm{C}$ and darkness.

\section{Effect of vase solution type on water relations, flower bud opening and vase life (experiment 1 )}

It was investigated whether the type of vase solution affects flower bud opening and vase life, as well as whether this effect depends on cut flower water relations. The night before the experiment, the cut flowers were kept in the dark refrigerated storage $\left(2^{\circ} \mathrm{C}\right)$ for $12 \mathrm{~h}$, to ensure maximal hydration (Fanourakis et al., 2012, 2016b). Next day, vase life was determined on cut flowers that were placed in the vase (one flower per flask; Supplemental Figures S1 and S2). The vases contained $250 \mathrm{~mL}$ vase solution, which was (a) tap water, (b) deionized water (i.e., water that is deficient of all dissolved substances), or (c) Van Meeteren solution $\left(0.7 \mathrm{mM} \mathrm{CaCl} \cdot 2 \mathrm{H}_{2} \mathrm{O}, 1.5 \mathrm{mM} \mathrm{NaHCO}_{3}, 5 \mathrm{M} \mathrm{CuSO}_{4} \cdot 5 \mathrm{H}_{2} \mathrm{O}\right.$; Van Meeteren et al., 1999). Vases were arranged on benches in a randomized complete block design. The top of the flasks was covered with aluminum foil (Supplemental Figures S1 and S2), to ensure that water loss could only occur via the flower stalks. The flasks were placed in a climate-controlled room at $22^{\circ} \mathrm{C}, 50 \% \mathrm{RH}$ and a light intensity of $15 \mathrm{mmol} \mathrm{m}^{-2} \mathrm{~s}^{-1}$ for $12 \mathrm{~h}$ per day, provided by fluorescent tubes (Pars Shahab Lamp Co., Tehran, Iran). As an indication of air velocity, the rate of evaporation from two glass beakers was recorded in the test room during measurements $( \pm 0.0001 \mathrm{~g}$; Mettler AE 200, Giessen, Germany). The evaporation rate of distilled water was $0.73 \pm 0.01 \mathrm{mmol} \mathrm{H}_{2} \mathrm{O} \mathrm{m}^{-2} \mathrm{~s}^{-1}$, indicating adequate air circulation (Seif et al., 2021). The height of the vase solution column was held constant at $7 \pm 1 \mathrm{~cm}$ over the evaluation period to avoid hydrostatic pressure differences between flowers with different transpiration rates (Fanourakis et al., 2012, 2016b). Different treatments were assessed simultaneously. Daily, the flower and flask weights were separately recorded at the onset of photoperiod $( \pm 0.01 \mathrm{~g}$; MXX-412; Denver Instruments, Bohemia, NY, U.S.A.). The fresh weight of each flowering stem was expressed relative to its initial weight. The transpiration rate was calculated per unit initial fresh weight (Fanourakis et al., 2020b). The flower diameter was daily recorded during vase life. In cut carnation, this was done by assessing the maximum diameter together with the diameter perpendicularly to that one, and finally averaging these two values (Fanourakis et al., 2012). In cut rose, the maximum diameter was only measured.

Flower quality was daily determined, while end of cut flower vase life was based on the occurrence of at least one of the following criteria: (i) bending of the pedicel (i.e., flower angle becomes larger than $90^{\circ}$ from the vertical position); (ii) abscission of more than two petals; (iii) visible wilting of the flower (i.e., loss of petal turgor); and (iv) more than $50 \%$ of the number of leaves had abscised, turned yellow, or had desiccated (VBN, 2005). To reduce subjectivity, three observers independently evaluated the end of vase life (with- 
out being aware of treatment assignment), and decision was based on majority vote (Fanourakis et al., 2020b). In this study, no Botrytis cinerea infections were observed. Twelve flowers per treatment were assessed in three cultivars per species (carnation: 'White Liberty', 'Grand Slam', 'Kirsi'; rose: 'Samurai', 'Avalanche', 'Sorbet').

\section{The role of microbes on raising vase life differences owing to vase solution type (experiment 2 )}

It was also investigated whether microbial growth mediates the effect of vase solution type on vase life. This was done by preventing microbial growth via using a biocide. Cut flowers were kept in dark refrigerated storage $\left(2^{\circ} \mathrm{C}\right)$ for $12 \mathrm{~h}$ before experimentation. For vase life evaluation, the experimental procedures and conditions were identical with experiment 1 , besides the extended range of vase solutions. The following six vase solution types were applied: (a) tap water, (b) deionized water, (c) Van Meeteren solution, and (d-f) each of these three including 200 ppm 8-hydroxyquinoline sulfate (8-HQS). Eight flowers per treatment were assessed in cut rose cv. 'Avalanche'.

\section{Effect of vase solution type on vase life of cut roses that} were previously partly desiccated (experiment 2)

It may be expected that the vase solution type is also important in determining vase life of roses that were previously held dry (the so-called dry storage), and thus were partly desiccated before placement into the vase (Fanourakis et al., 2016b). This effect was therefore addressed in cut flowers that were previously desiccated to a predefined percentage of initial weight (Fanourakis et al., 2016b). Fully-hydrated cut flowers were taken from refrigerated storage $\left(2^{\circ} \mathrm{C}\right.$ and darkness). The vase life was determined on cut flowers that were placed in the vase upon arrival (i.e., 100\% fresh weight) or following $15 \%$ loss of initial (saturated) fresh weight (i.e., $85 \%$ fresh weight). In the latter case, the cut flowers were placed in empty vases in the test room, and cut flower weight was periodically recorded (every $15 \mathrm{~min} ; \pm 0.01 \mathrm{~g}$; MXX-412; Denver Instruments, Bohemia, NY, U.S.A.) until it reached the predefined value. Test room conditions were air temperature

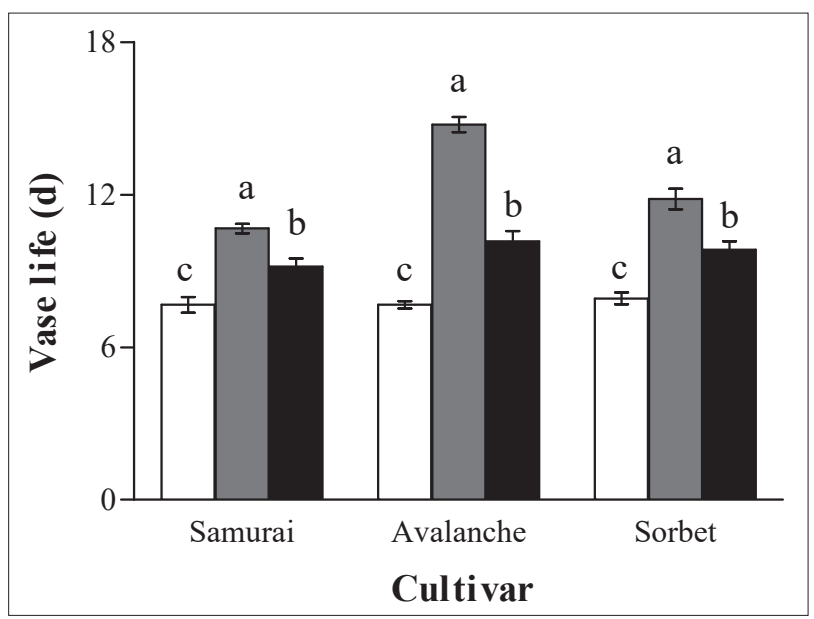

FIGURE 1. Vase life as a function of vase solution type [tap water (white columns), deionized water (grey columns), Van Meeteren solution (black columns)] in three cut rose cultivars. Prior to evaluation, stem length was normalized to $45 \mathrm{~cm}$, while cut flowers were of similar weight and wellhydrated. Different letters indicate significant differences at $P=0.05$ level (tested per cultivar). Values are the mean of 12 cut flowers \pm sem. of $25.0 \pm 0.2^{\circ} \mathrm{C}, \mathrm{RH}$ equal to $50 \pm 3 \%$, and light intensity of $50 \mathrm{mmol} \mathrm{m}^{-2} \mathrm{~s}^{-1}$ provided by fluorescent lamps (Pars Shahab Lamp Co., Tehran, Iran). The employed environmental conditions are typical for dehydration experiments (Giday et al., 2015; Carvalho et al., 2016; Seif et al., 2021). For vase life evaluation, the experimental procedures and conditions were identical with experiment 1 , including the three vase solution types [i.e., (a) tap water, (b) deionized water, and (c) Van Meeteren solution]. Eight flowers per treatment were assessed in cut rose cv. 'Avalanche'.

\section{Effect of vase solution type on rehydration ability of cut roses that were previously partly desiccated (experiment 2)}

The effect of vase solution type on rehydration ability of roses that were previously partly desiccated was also evaluated. Cut flowers were taken from refrigerated storage, and allowed to dehydrate to different percentages of weight loss $(0,5,15,25$, and $30 \%$ of the initial weight; \pm 0.01 g; MXX412; Denver Instruments, Bohemia, NY, U.S.A.). Dehydration procedure and test room conditions are given in the previous section. Then the cut stem ends were immediately placed in buckets filled with one of the three vase solution types [i.e., (a) tap water, (b) deionized water, and (c) Van Meeteren solution] at a height of $12 \mathrm{~cm}$. Afterwards, the cut flowers were incubated for $24 \mathrm{~h}$ in the refrigerated storage $\left(2^{\circ} \mathrm{C}\right.$ and darkness). Subsequently, cut flower weight was measured. The rehydration method used was independent of the water loss (stomatal) component (Giday et al., 2014). Cut flower weight was established by the balance between water uptake (through the stem cut end) and water loss (through transpiration). The latter was minimized by applying a very low VPD and darkening. Measurements were conducted on ten replicates in cut rose cv. 'Avalanche'.

\section{Statistical design and analysis}

Data analysis was performed using the $\mathrm{R}$ software (v. 2.14.2; www.r-project.org). A factorial experiment was realized based on a completely randomized design (Factor A: vase solution type; Factor B: cultivar; experiment 1). The

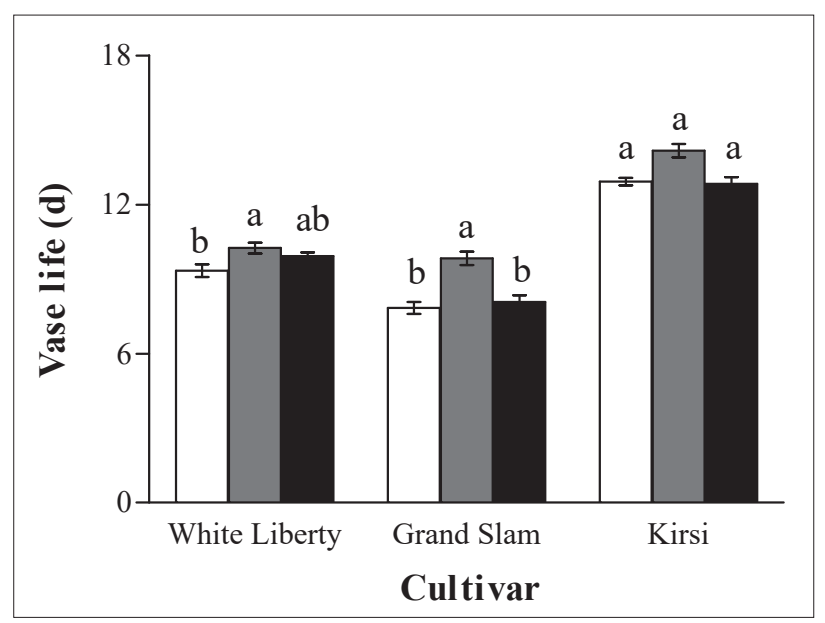

FIGURE 2. Vase life as a function of vase solution type [tap water (white columns), deionized water (grey columns), Van Meeteren solution (black columns)] in three cut carnation cultivars. Prior to evaluation, stem length was normalized to $40 \mathrm{~cm}$, while cut flowers were of similar weight and wellhydrated. Different letters indicate significant differences at $P=0.05$ level (tested per cultivar). Values are the mean of 12 cut flowers \pm sem. 
same was also performed for the first (Factor A: vase solution type; Factor B: treatment) and second (Factor A: vase solution type; Factor B: weight before rehydration) part of the next experiment (experiment 2). Data were firstly tested for normality (Shapiro-Wilk test) and homogeneity of variances (Levene's test). Treatment effects were then determined at $5 \%$ probability level and mean separation was carried out using least significant differences based on Tukey's $t$-test $(P \leq 0.05)$.

\section{Results}

Deionized water as vase solution promotes flower bud opening and vase life through improved water balance owing to enhanced water uptake

Vase life evaluations were conducted in rose and carnation (three cultivars each), by employing three types of vase solution (tap water, deionized water, and Van Meeteren solution).

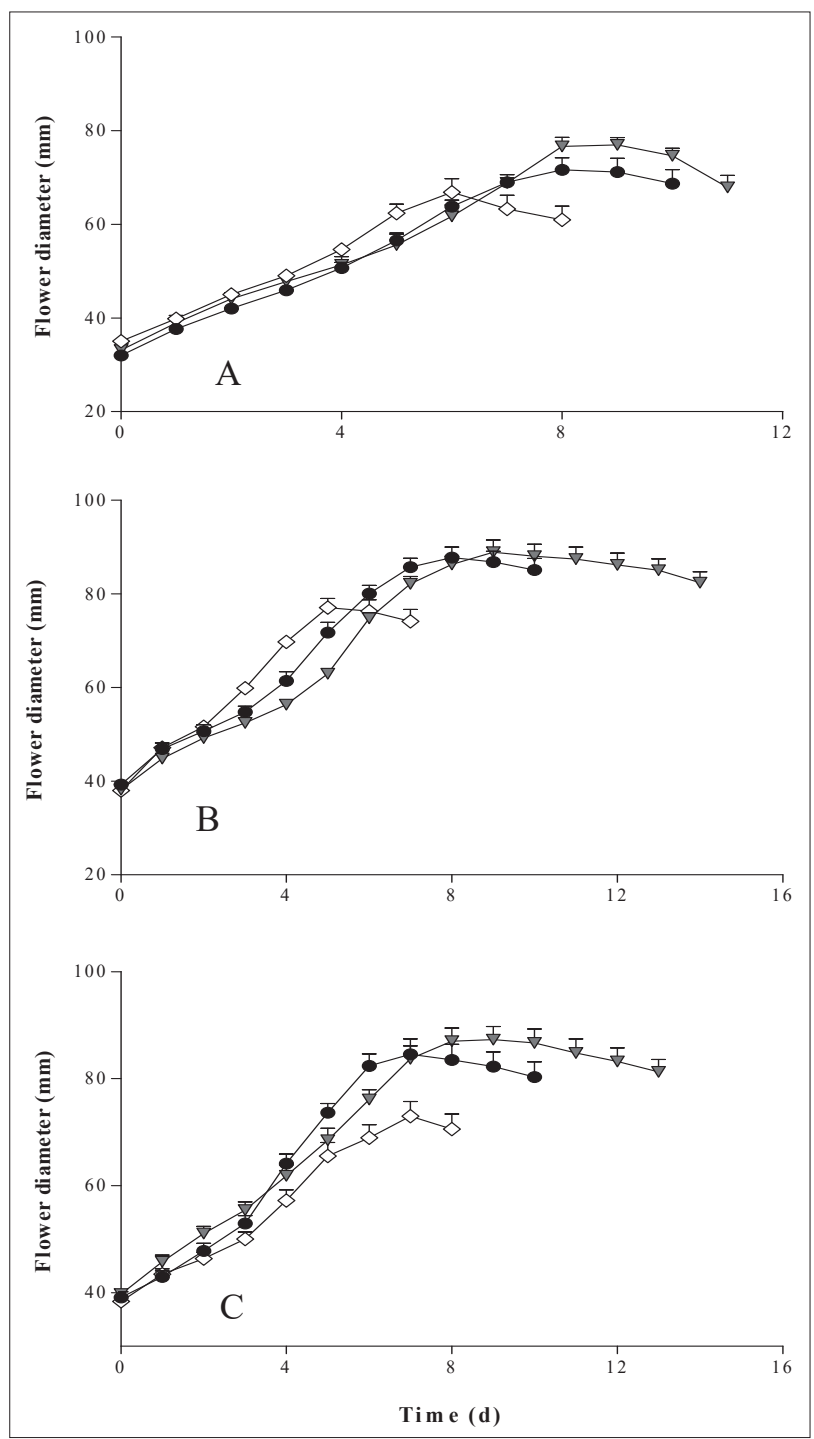

FIGURE 3. Flower bud (maximum) diameter during vase life as a function of vase solution type [tap water (open symbols), deionized water (grey symbols), Van Meeteren solution (black symbols)] in three cut rose cultivars (A, 'Samurai'; B, 'Avalanche'; C, 'Sorbet'). Values are the mean of 12 cut flowers \pm sem. When the sem bars are not visible, the sem is smaller than the symbol.
In both species, using deionized water as vase solution clearly promoted vase life, as compared to the other two vase solution types (Figures 1 and 2; see also Supplemental Figures S1 and S2). In rose, the Van Meeteren solution led to longer vase life as compared to tap water (Figure 1), whereas this trend was only apparent in one out of three cultivars of carnation (Figure 2).

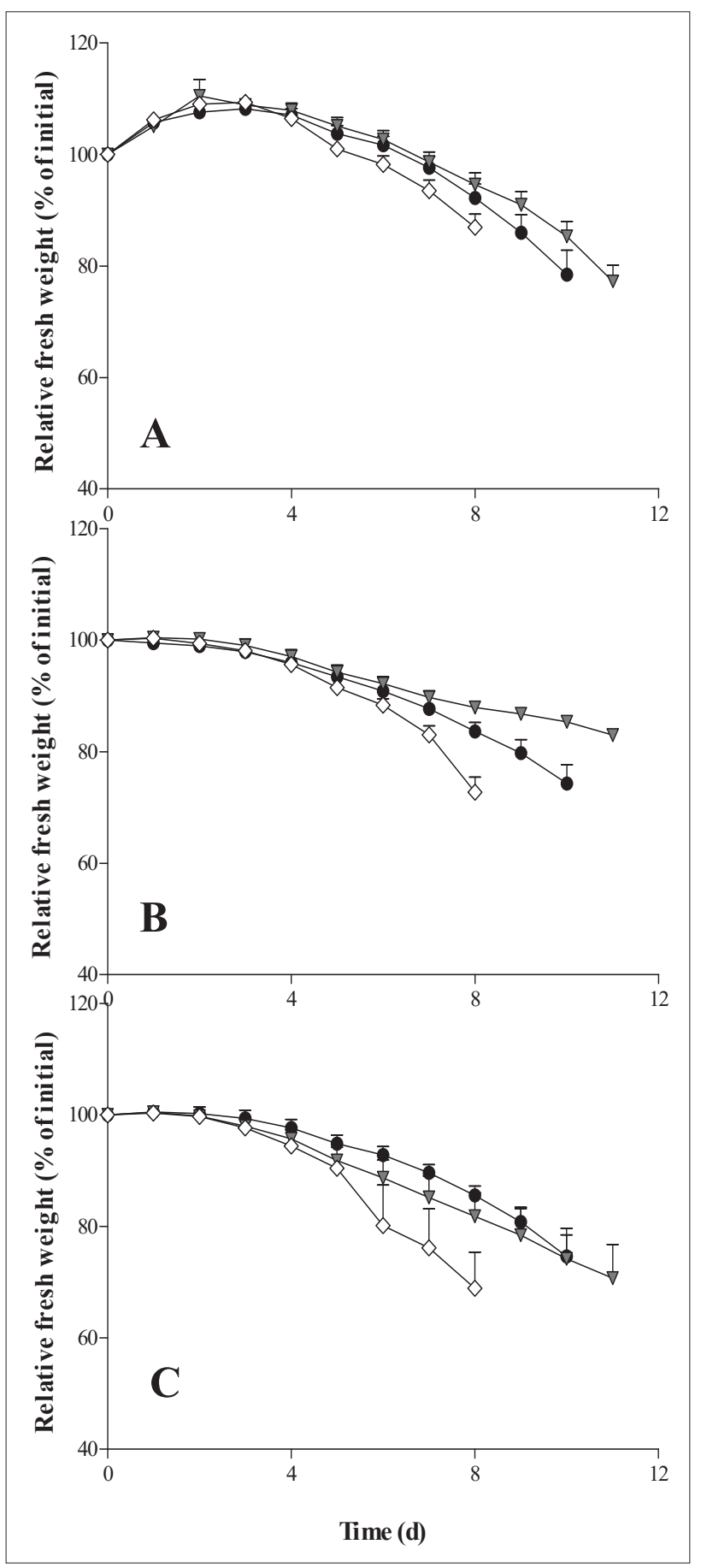

FIGURE 4. Relative fresh weight during vase life as a function of vase solution type [tap water (open symbols), deionized water (grey symbols), Van Meeteren solution (black symbols)] in three cut rose cultivars (A, 'Samurai'; B, 'Avalanche'; C, 'Sorbet'). Cut flowers were of similar weight and well-hydrated. The fresh weight of each flowering stem was expressed relative to its initial weight. Values are the mean of 12 cut flowers \pm sem. When the sem bars are not visible, the sem is smaller than the symbol. 


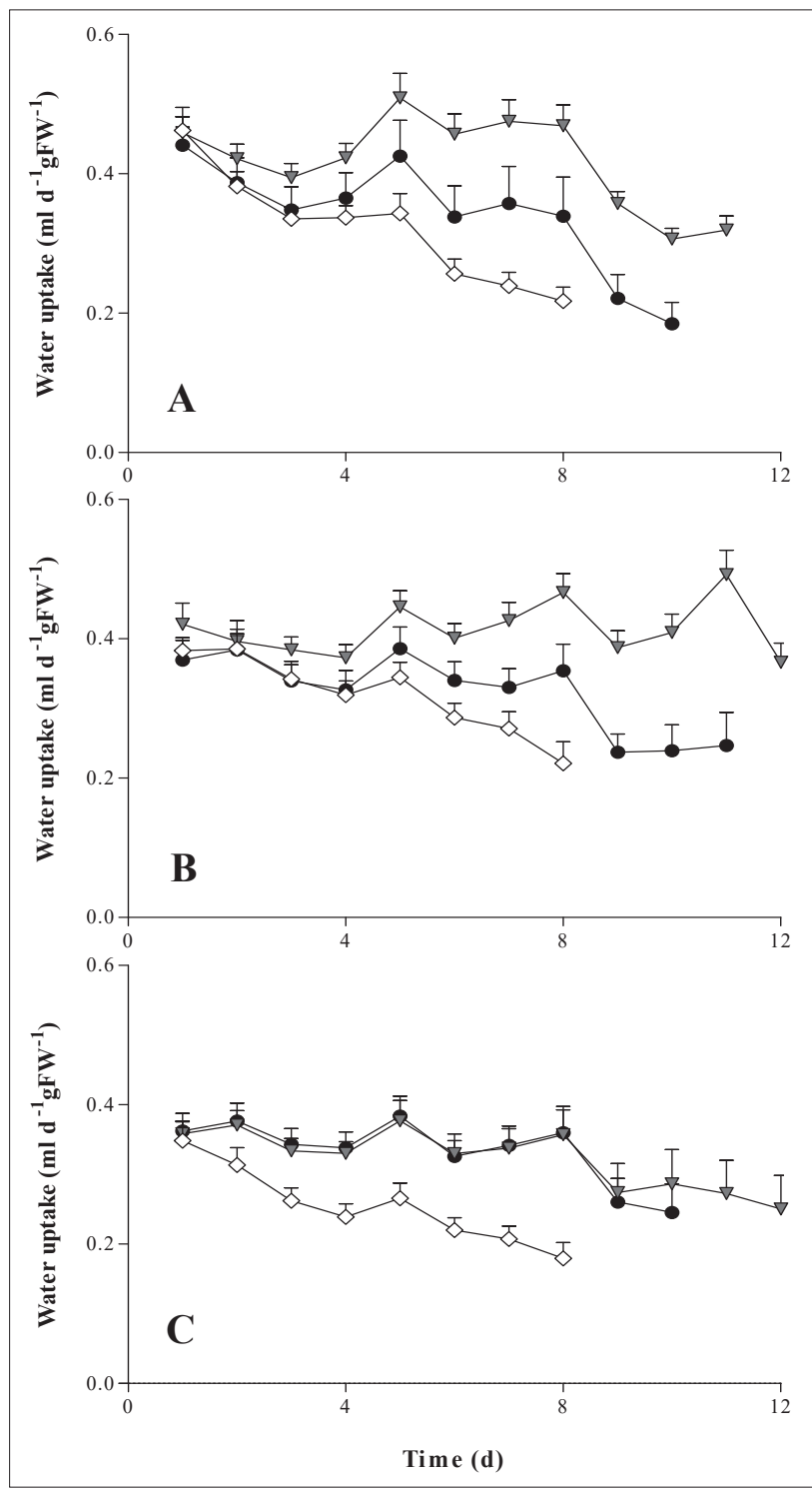

FIGURE 5. Water uptake rate during vase life as a function of vase solution type [tap water (open symbols), deionized water (grey symbols), Van Meeteren solution (black symbols)] in three cut rose cultivars (A, 'Samurai'; B, 'Avalanche'; C, 'Sorbet']. The water uptake was expressed per unit of time and cut flower fresh weight (FW). Values are the mean of 12 cut flowers \pm sem. When the sem bars are not visible, the sem is smaller than the symbol.

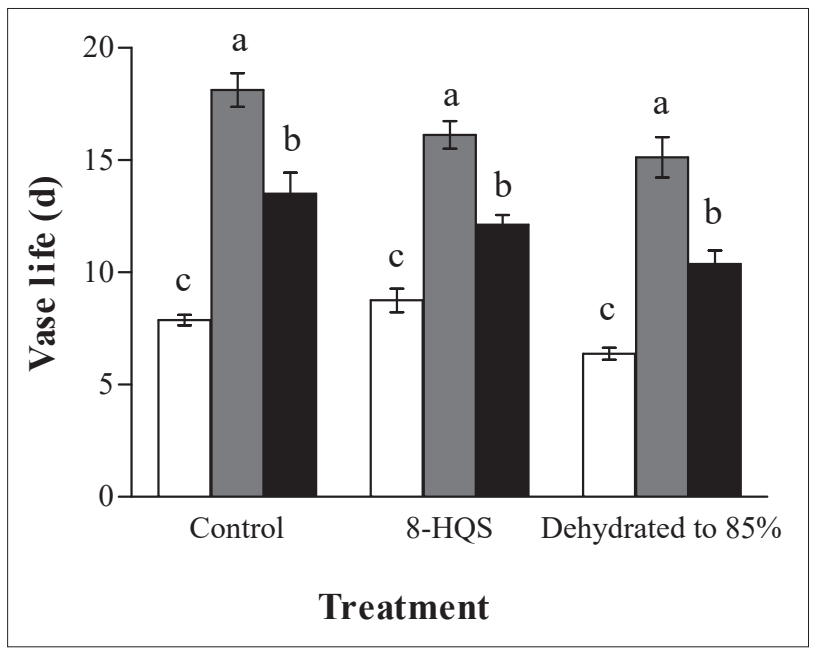

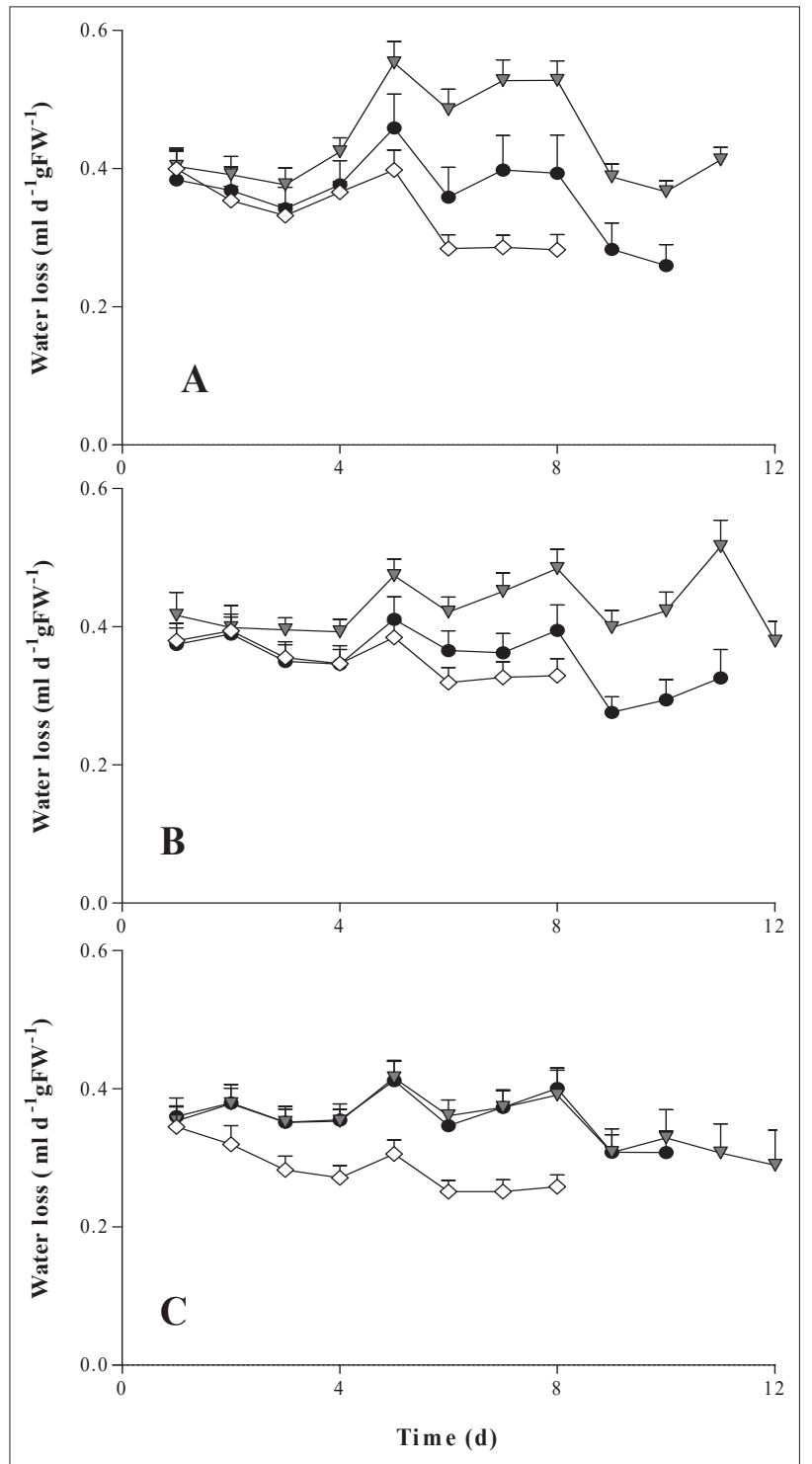

FIGURE 6. Water loss rate during vase life as a function of vase solution type [tap water (open symbols), deionized water (grey symbols), Van Meeteren solution (black symbols)] in three cut rose cultivars (A, 'Samurai'; B, 'Avalanche'; C, 'Sorbet'). The water loss was expressed per unit of time and cut flower fresh weight (FW). Values are the mean of 12 cut flowers \pm sem. When the sem bars are not visible, the sem is smaller than the symbol.

FIGURE 7. Vase life as a function of vase solution type [tap water (white columns), deionized water (grey columns), Van Meeteren solution (black columns)] in cut rose cultivar 'Avalanche'. Assessments included fully-hydrated flowers placed on (i) the three types of vase solution (control), or (ii) these combined with biocide (8-HQS), as well as (iii) partly-dehydrated flowers (to $85 \%$ of initial weight) placed on the three types of vase solution (dehydrated to $85 \%)$. Different letters indicate significant differences at $P=0.05$ level (tested per treatment). Values are the mean of 8 cut flowers \pm sem. 
Deionized water as holding solution not only promoted flower opening, but also sustained the maximum flower opening phase for a longer period (Figure 3; Supplemental Figure S3). This effect was more pronounced on rose (Figure 3), as compared to carnation (Supplemental Figure S3). The Van Meeteren solution generally led to a flower opening state in between the other two vase solution types (Figure 3; Supplemental Figure S3).

In both taxa, using deionized water led to improved water balance (i.e., lower fresh weight depression) during vase life, as compared to tap water (Figure 4; Supplemental Figure S4). In most cases, the Van Meeteren solution led to a water balance in between deionized water and tap water treat-

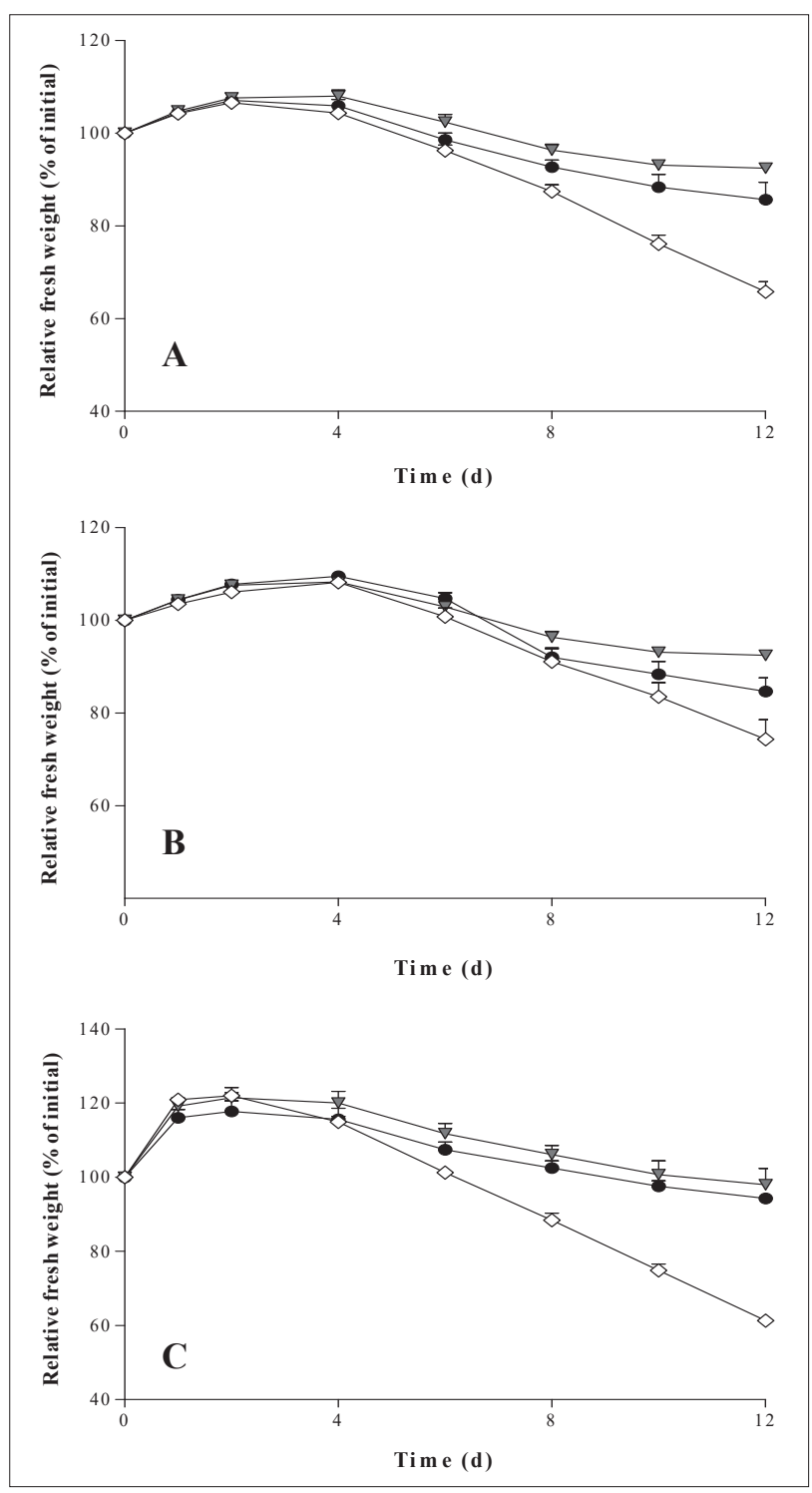

FIGURE 8. Relative fresh weight during vase life as a function of vase solution type [tap water (open symbols), deionized water (grey symbols), Van Meeteren solution (black symbols)] in cut rose cultivar 'Avalanche'. Assessments included fully-hydrated flowers placed on (i) the three types of vase solution (A), or (ii) these combined with biocide (8HQS; B), as well as (iii) partly-dehydrated flowers (to $85 \%$ of initial weight) placed on the three types of vase solution (C). Cut flowers were of similar weight. The fresh weight of each flowering stem was expressed relative to its initial weight. Values are the mean of 8 cut flowers \pm sem. When the sem bars are not visible, the sem is smaller than the symbol. ments (Figure 4; Supplemental Figure S4).

In either species, using deionized water led to enhanced water uptake in the course of vase life, as compared to tap water (Figure 5; Supplemental Figure S5). In most cases, the Van Meeteren solution led to a water uptake in between deionized water- and tap water- placed cut flowers (Figure 5; Supplemental Figure S5).

The effect of vase solution on water loss was cultivarand species-dependent. Cut roses held in deionized water showed higher water loss rates during vase life, as compared to the ones placed in tap water (Figure 6). In carnation, this trend was observed in one out of three cultivars (Supplemental Figure S6).

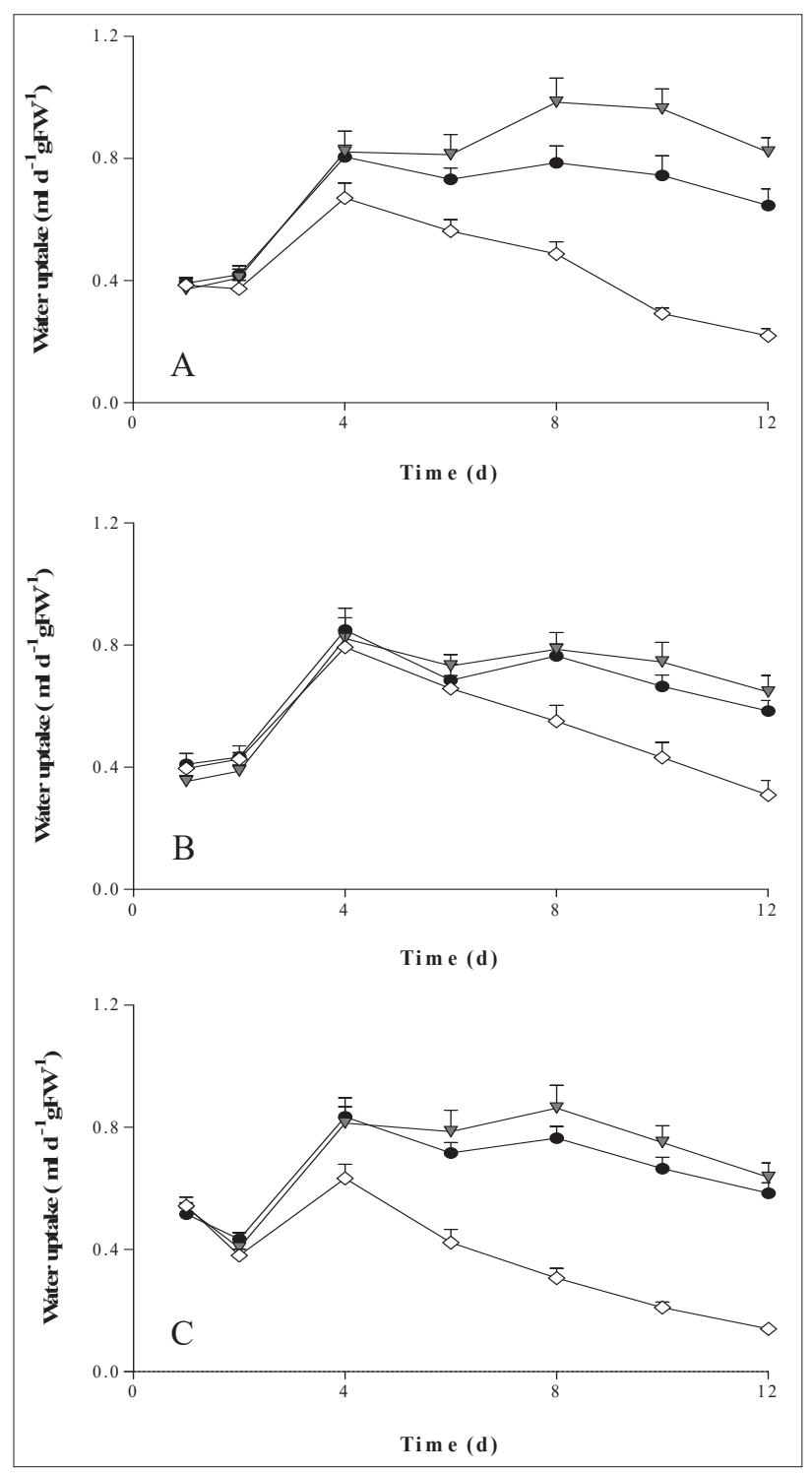

FigURE 9. Water uptake rate during vase life as a function of vase solution type [tap water (open symbols), deionized water (grey symbols), Van Meeteren solution (black symbols)] in cut rose cultivar 'Avalanche'. Assessments included fully-hydrated flowers placed on (i) the three types of vase solution (A), or (ii) these combined with biocide (8HQS; B), as well as (iii) partly-dehydrated flowers (to $85 \%$ of initial weight) placed on the three types of vase solution (C). The water uptake was expressed per unit of time and cut flower fresh weight (FW). Values are the mean of 8 cut flowers \pm sem. When the sem bars are not visible, the sem is smaller than the symbol. 
The vase solution effect on water uptake and vase life is consistent following biocide use or preceding mild desiccation

Based on experiment 1 (Figure 1), one rose cultivar ('Avalanche') was selected, at which the type of vase solution exerted a pronounced effect on vase life.

Similarly to experiment 1 (Figure 1), using deionized water resulted to the longest vase life followed by the Van Meeteren solution, while tap water led to the shortest vase life (Figure 7). The same trend also noted either upon adding a biocide (8-HQS) in each vase solution type or when cut flowers were partly desiccated (to $85 \%$ of initial weight) prior to vase life evaluation (Figure 7).

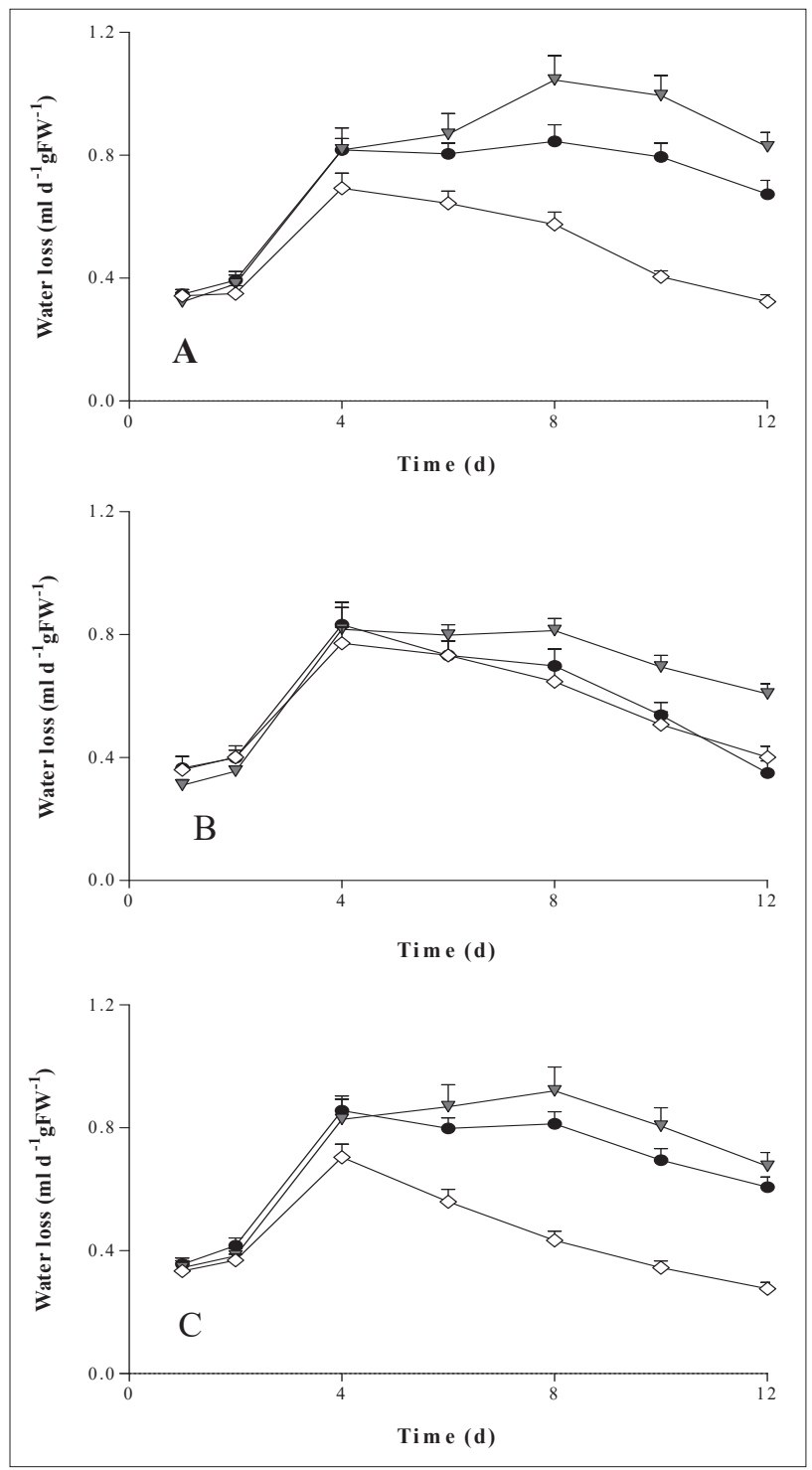

FIGURE 10. Water loss rate during vase life as a function of vase solution type [tap water (open symbols), deionized water (grey symbols), Van Meeteren solution (black symbols)] in cut rose cultivar 'Avalanche'. Assessments included fully-hydrated flowers placed on (i) the three types of vase solution (A), or (ii) these combined with biocide (8HQS; B), as well as (iii) partly-dehydrated flowers (to $85 \%$ of initial weight) placed on the three types of vase solution (C). The water loss was expressed per unit of time and cut flower fresh weight (FW). Values are the mean of 8 cut flowers \pm sem. When the sem bars are not visible, the sem is smaller than the symbol.
The vase solution effect on water balance (Figure 8), uptake (Figure 9) and loss (Figure 10) was consistent with experiment 1 (Figures 4-6), and was not altered by including biocide or by using partly-desiccated cut flowers.

\section{Deionized water stimulates rehydration potential following mild desiccation}

For mildly-desiccated (i.e., $\geq 85 \%$ of initial fresh weight) cut flowers, deionized water, employed as rehydration medium, enhanced fresh weight recovery, as compared to tap water (Figure 11). For severely-desiccated (i.e., $\leq 70 \%$ of initial fresh weight), the opposite trend was apparent (Figure 11).

\section{Discussion}

By processing the materials and methods of 80 vase life studies, it became apparent that deionized water is the most widely used holding solution (44\% of the studies), followed by tap water (30\% of the studies; Fanourakis et al., 2015). To date, the Van Meeteren solution has not gained a wide acceptance in vase life experiments (Fanourakis et al., 2015). The aim of the present study was to evaluate the effect of holding solution type on water relations, flower bud opening and cut flower longevity in a range of cultivars of carnation as well as rose.

Cut flowers of either species held in deionized water had consistently longer vase life (Figures 1, 2 and 7; see also Supplemental Figures S1 and S2) and enhanced flower opening which persisted for a longer period (Figure 3; Supplemental Figure S3), as compared to those placed in tap water. Cut flowers held in Van Meeteren solution mostly showed an intermediate vase life (Figures 1, 2 and 7) and flower opening (Figure 3; Supplemental Figure S3), as compared to cut flowers placed in tap and deionized waters. A positive effect of deionized water on vase life, as compared to the Van Meeteren solution, has been shown in Baeckea frutescens and Chamelaucium uncinatum, while no significant effect was apparent in Acacia holosericea and cut chrysanthemum cv. 'Dark Splendid Reagan' (Damunupola et al., 2010). Contrary to these findings, a negative effect of deion-

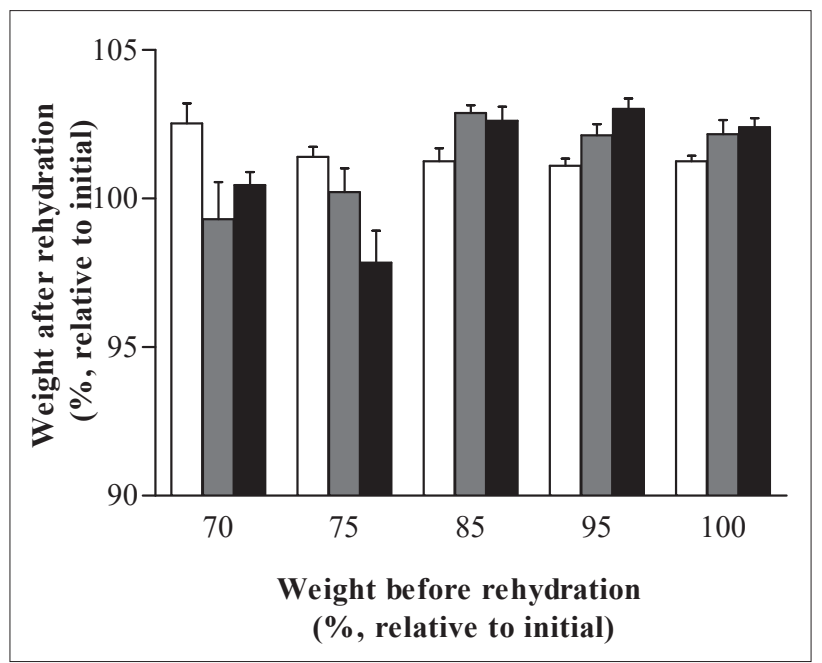

FIGURE 11. Rehydration potential $\left(24 \mathrm{~h}\right.$ at darkness and $\left.2^{\circ} \mathrm{C}\right)$ as a function of vase solution type [tap water (open symbols), deionized water (grey symbols), Van Meeteren solution (black symbols)] in cut rose cultivar 'Avalanche'. Prior to rehydration, flowers had been partly-dehydrated (i.e., lost 0 , $5,15,25$, and $30 \%$ of initial weight). Cut flowers were of similar weight. Values are the mean of 10 cut flowers \pm sem. 
ized water on vase life has been reported for cut chrysanthemum cv. 'Cassa' (Van Meeteren et al., 1999). Our results together with those of Damunupola et al. (2010) make clear that deionized water exerts a promotive effect on vase life of most cut flower species, while the case reported by Van Meeteren et al. (1999) seems to be an exception, possibly associated with the employed cultivar (Van Doorn, 2012). For the first time, we also show that both flower bud opening and the maximum flower opening phase were also enhanced by deionized water, as compared to tap water.

We further show that the enhanced flower opening and vase life of either species held in deionized water, as compared to Van Meeteren solution or tap water, is clearly related to improved cut flower water balance throughout vase life (Figures 4 and 8; Supplemental Figure S4). This improved water balance has been associated with a reduction in both the extent and the rate of fresh weight depression (Figures 4 and 8; Supplemental Figure S4). By considering the fresh weight following vase life termination, Damunupola et al. (2010) reported that deionized water led to a lower fresh weight decrease in Baeckea frutescens and Chamelaucium uncinatum as compared to the Van Meeteren solution, while an opposite effect was noted in Acacia holosericea. Taken together these results, it becomes apparent that the holding solution effects on flower opening and vase life are underlain by the cut flower water balance, while this effect gradually develops in the course of vase life.

For the first time, the two components of water balance (i.e., loss and uptake) were here simultaneously addressed throughout vase life (resolution per day). This analysis showed that the improved water balance of cut flowers held in deionized water, as compared to either tap water or Van Meeteren solution, is related to improved water uptake in both species under study (Figures 5 and 9; Supplemental Figure S5). By measuring the holding solution weight at the end of vase life (i.e., resolution per vase life period), Damunupola et al. (2010) reported that deionized water led to a better water uptake in Baeckea frutescens and Chamelaucium uncinatum as compared to the Van Meeteren solution, while an opposite effect was noted in Acacia holosericea. Since the effect of holding solution type on water loss varied depending on the species and the cultivar under study (Figure 6; Supplemental Figure S6), it becomes apparent that the enhanced water uptake is the key player in determining the improved water balance of cut flowers held in deionized water, as compared to the other two types of holding solution.

Assessments of the current study were limited to cut flowers which were grown at the onset of autumn. Wintercultivated cut flowers are generally characterized by shorter longevity as compared to the remaining growing seasons, owing to both reduced light intensity (Fanourakis et al., 2019a) and increased RH (Fanourakis et al., 2019b). These two conditions have been associated with impaired stomatal closing ability (Fanourakis et al., 2020a). In cut flowers undergoing excessive transpiration, unhampered water uptake is a prerequisite for long vase life (Fanourakis et al., 2012). Under this background, it may be expected that the promotive effect of deionized water on vase life through improved water uptake, will be more prominent in winter-cultivated cut flowers, which typically show attenuated regulation of transpiration.

The microbial load may be higher in tap water, as compared to deionized water, which has been mechanically filtered or processed. A higher microbial load would cause vascular blockage leading to low water uptake (Fanourakis et al., 2012). In addition, literature reports that $\mathrm{Cu}^{2+}$ (one of the components of Van Meeteren solution) may inhibit microbial growth (Damunupola et al., 2010; Ratnayake et al., 2011; Van Doorn, 2012), though this action has been lately questioned (Ratnayake et al., 2012). Under this background, we also tested whether the noted variation in vase life among the three vase solution types may be attributed to differences in microbial load. This hypothesis was not validated, since the relative difference among the three vase solution types in vase life (Figure 7), as well as the underlying parameters [e.g., water balance (Figure 8) and uptake (Figure 9)], was not affected by blocking microbial growth (via using a biocide). Therefore, the improved water uptake of cut flowers held in deionized water, underlying the enhanced flower bud opening (Figure 3; Supplemental Figure S3) and the longer vase life (Figures 1, 2 and 7), as compared to the other two holding solution types, is not related to differences in microbial load.

Literature also reports that $\mathrm{Cu}^{2+}$ (one of the components of Van Meeteren solution) is possibly related to ethylene biosynthesis and action (Ratnayake et al., 2011). This hypothesis was also found to be false, since employing deionized water (free of $\mathrm{Cu}^{2+}$ ) resulted to longer vase life, as compared to the Van Meeteren solution (containing $\mathrm{Cu}^{2+}$ ), in carnation (Figure 2). This species is highly sensitive to ethylene, and thus any influence on it would have induced a pronounced effect on cut flower longevity (Onozaki, 2018).

Cut flowers are often held out of water during the supply chain (often referred to as dry storage), experiencing water deprivation and thus decreased hydration status (Fanourakis et al., 2016b). We show that deionized water, as hydration medium, led to enhanced fresh weight recovery as compared to tap water in mildly-desiccated (up to $85 \%$ of initial weight) cut flowers (Figure 11). Moreover, the present study for the first time also shows that deionized water led to longer vase life in cut roses that were previously desiccated (as those experiencing dry-handling), as compared to either Van Meeteren solution or tap water (Figure 7). Just like fully-hydrated flowers, this promotive effect of deionized water on vase life was underlain by improved water balance throughout vase life (Figure 8) owing to enhanced water uptake (Figure 9).

Dehydration was still reversible (i.e., full hydration) when severely-desiccated cut flowers (i.e., $\leq 70 \%$ of initial fresh weight) were hydrated by using tap water (Figure 11). Instead, reduced and incomplete recovery (rehydration) of severely-desiccated cut flowers following hydration was noted when employing deionized water or Van Meeteren solution (Figure 11). Under this very low hydration status, where vase life is severely decreased (by 50\%; Fanourakis et al., 2016b), using tap water seems to be preferable in terms of hydration. Under these severe water stress conditions, the increased cation content of tap water may have improved stem hydraulic conductance (Van Meeteren et al., 1999), facilitating rehydration.

\section{Conclusions}

Deionized water is mostly employed as holding solution in vase life studies, followed by tap water. The Van Meeteren solution (deionized water containing $\mathrm{CuSO}_{4}, \mathrm{CaCl}_{2}$ and $\mathrm{NaHCO}_{3}$ at low concentrations) has yet not been widely used. The effect of these holding solution alternatives on flower bud opening and vase life of carnation and rose was here evaluated, together with the underlying processes. In both 
taxa, deionized water led to longest vase life and enhanced flower bud opening which persisted for a longer period, whereas tap water yielded to the shortest vase life and reduced flower opening. This stimulation in both flower bud opening and vase life was the result of enhanced water balance throughout vase life, owing to improved water uptake. The noted effects were not related to differences in microbial growth. Deionized water also promoted both rehydration ability and vase life in cut roses which were mildly desiccated (up to $85 \%$ of initial weight) prior to evaluation. It is concluded that deionized water as vase solution prolongs vase life and promotes flower bud opening, and this effect is related to enhanced water uptake.

\section{Acknowledgments}

This research was financed by Lorestan University (Iran). We thank the laboratory staff for their contributions, continued diligence, and dedication to their craft. The authors also wish to thank Dr. Roland Pieruschka for critically reviewing the manuscript. The valuable comments of the editor and four anonymous reviewers are greatly acknowledged.

\section{References}

Carvalho, D.R.A., Koning-Boucoiran, C.F.S., Fanourakis, D., Vasconcelos, M.W., Carvalho, S.M.P., Heuvelink, E., Krens, F.A., and Maliepaard, C. (2015). QTL analysis for stomatal functioning in tetraploid Rosa $\times$ hybrida grown at high relative air humidity and its implications on postharvest longevity. Mol. Breeding 35, 172. https://doi.org/10.1007/s11032-015-0365-7.

Carvalho, D.R.A., Fanourakis, D., Correia, M.J., Monteiro, J.A., AraújoAlves, J.P.L., Vasconcelos, M.W., Almeida, D.P.F., Heuvelink, E., and Carvalho, S.M.P. (2016). Root-to-shoot ABA signaling does not contribute to genotypic variation in stomatal functioning induced by high relative air humidity. Environm. Exp. Bot. 123, 13-21. https:// doi.org/10.1016/j.envexpbot.2015.11.001.

Damunupola, J.W., Qian, T., Muusers, R., Joyce, D.C., Irving, D.E., and Van Meeteren, U. (2010). Effect of S-carvone on vase life parameters of selected cut flower and foliage species. Postharvest Biol. Technol. 55, 66-69. https://doi.org/10.1016/j.postharvbio.2009.07.009.

Fanourakis, D., Carvalho, S.M.P., Almeida, D.P.F., Van Kooten, O., Van Doorn, W.G., and Heuvelink, E. (2012). Postharvest water relations in cut rose cultivars with contrasting sensitivity to high relative air humidity during growth. Postharvest Biol. Technol. 64, 64-73. https://doi.org/10.1016/j.postharvbio.2011.09.016.

Fanourakis, D., Pieruschka, R., Savvides, A., Macnish, A.J., Sarlikioti, V., and Woltering, E.J. (2013). Sources of vase life variation in cut roses: A review. Postharvest Biol. Technol. 78, 1-15. https://doi. org/10.1016/j.postharvbio.2012.12.001.

Fanourakis, D., Velez-Ramirez, A.I., In, B.C., Barendse, H., Van Meeteren, U., and Woltering, E.J. (2015). A survey of preharvest conditions affecting the regulation of water loss during vase life. Acta Hortic. 1064, 195-204. https://doi.org/10.17660/ ActaHortic.2015.1064.22.

Fanourakis, D., Bouranis, D., Giday, H., Carvalho, D.R.A., Rezaei Nejad, A., and Ottosen, C.O. (2016a). Improving stomatal functioning at elevated growth air humidity: A review. J. Plant Physiol. 207, 51-60. https://doi.org/10.1016/j.jplph.2016.10.003.

Fanourakis, D., Giday, H., Li, T., Kambourakis, E., Ligoxigakis, E.K., Papadimitriou, M., Strataridaki, A., Bouranis, D., Fiorani, F., Heuvelink, E., and Ottosen, C.O. (2016b). Antitranspirant compounds alleviate the mild-desiccation-induced reduction of vase life in cut roses. Postharvest Biol. Technol. 117, 110-117. https://doi.org/10.1016/j. postharvbio.2016.02.007.
Fanourakis, D., Hyldgaard, B., Giday, H., Aulik, I., Bouranis, D., Körner, O., and Ottosen, C.O. (2019a). Stomatal anatomy and closing ability is affected by supplementary light intensity in rose (Rosa hybrida L.). Hortic. Sci. (Prague) 46, 81-89. https://doi. org/10.17221/144/2017-HORTSCI.

Fanourakis, D., Giday, H., Hyldgaard, B., Bouranis, D., Körner, O., and Ottosen, C.O. (2019b). Low air humidity during growth promotes stomatal closure ability in potted roses (Rosa hybrida). Eur. J. Hortic. Sci. 84, 245-252. https://doi.org/10.17660/eJHS.2019/84.4.7.

Fanourakis, D., Aliniaeifard, S., Sellin, A., Giday, H., Körner, O., Rezaei Nejad, A., Delis, C., Bouranis, D., Koubouris, G., Kambourakis, E., Nikoloudakis, N., and Tsaniklidis, G. (2020a). Stomatal behavior following mid- or long-term exposure to high relative air humidity: A review. Plant Physiol. Biochem. 153, 92-105. https://doi. org/10.1016/j.plaphy.2020.05.024.

Fanourakis, D., Bouranis, D., Tsaniklidis, G., Rezaei Nejad, A., Ottosen, C.O., and Woltering, E.J. (2020b). Genotypic and phenotypic differences in fresh weight partitioning of cut rose stems: Implications for water loss. Acta Physiol. Plant. 42, 48. https://doi. org/10.1007/s11738-020-03044-w.

Giday, H., Fanourakis, D., Kjaer, K.H., Fomsgaard, I.S., and Ottosen, C.0. (2014). Threshold response of stomatal closing ability to leaf abscisic acid concentration during growth. J. Exp. Bot. 65, 43614370. https://doi.org/10.1093/jxb/eru216.

Giday, H., Kjaer, K.H., Ottosen, C.O., and Fanourakis, D. (2015). Cultivar differences in plant transpiration rate at high relative air humidity are not related to genotypic variation in stomatal responsiveness. Acta Hortic. 1064, 99-106. https://doi.org/10.17660/ ActaHortic.2015.1064.12.

Onozaki, T. (2018). Breeding of carnations (Dianthus caryophyllus L.) for long vase life. Breed Sci. 68, 3-13. https://doi.org/10.1270/ jsbbs.17091.

Pouri, H.A., Rezaei Nejad, A., and Shahbazi, F. (2017). Effects of simulated in-transit vibration on the vase life and post-harvest characteristics of cut rose flowers. Hortic. Environm. Biotechnol. 58, 38-47. https://doi.org/10.1007/s13580-017-0069-5.

Ratnayake, K., Bui, C.L., and Joyce, D.C. (2011). Copper distribution and ionic form effects for postharvest treatments of cut Acacia holosericea stems. Sci. Hortic. 130, 919-926. https://doi. org/10.1016/j.scienta.2011.09.015.

Ratnayake, K., Joyce, D.C., and Webb, R.I. (2012). Investigation of potential antibacterial action for postharvest copper treatments of cut Acacia holosericea. Postharvest Biol. Technol. 70, 59-69. https:// doi.org/10.1016/j.postharvbio.2012.04.004.

Reid, M.S., and Kofranek, A.M. (1980). Recommendations for standardized vase life evaluations. Acta Hortic. 113, 171-173. https://doi.org/10.17660/ActaHortic.1981.113.25.

Seif, M., Aliniaeifard, S., Arab, M., Mehrjerdi, M.Z., Shomali, A., Fanourakis, D., Li, T., and Woltering, E. (2021). Monochromatic red light during plant growth decreases the size and improves the functionality of stomata in chrysanthemum. Functional Plant Biol. 48(5), 515-528 https://doi.org/10.1071/FP20280.

Sørensen, H.K., Fanourakis, D., Tsaniklidis, G., Bouranis, D., Rezaei Nejad, A., and Ottosen, C.O. (2020). Using artificial lighting based on electricity price without a negative impact on growth, visual quality or stomatal closing response in Passiflora. Sci. Hortic. 267, 109354. https://doi.org/10.1016/j.scienta.2020.109354.

Van Doorn, W.G. (2012). Water relations of cut flowers. An update. Hortic. Rev. 40, 55-106. https://doi.org/10.1002/9781118351871.ch2.

Van Meeteren, U., Van Gelder, H., and Van Ieperen, W. (1999). Reconsideration of the use of deionized water as vase water in postharvest experiments on cut flowers. Postharvest Biol. Technol. 17, 175-187. https://doi.org/10.1016/S0925-5214(99)00050-2. 
VBN (2005). Evaluation cards for cut flowers (Leiden, The Netherlands: Association of Flower Auctions in The Netherlands (VBN)).

Xie, L., Joyce, D.C., Irving, D.E., and Eyre, J.X. (2008). Chlorine demand in cut flower vase solutions. Postharvest Biol. Technol. 47, 267-270. https://doi.org/10.1016/j.postharvbio.2007.06.019.

Received: Jul. 24, 2020

Accepted: Apr. 12, 2021

Addresses of authors:

Masoumeh Ahmadi-Majd ${ }^{1}$, Abdolhossein Rezaei Nejad ${ }^{1, *}$,

Sadegh Mousavi-Fard ${ }^{1}$ and Dimitrios Fanourakis ${ }^{2}$

${ }^{1}$ Department of Horticultural Sciences, Faculty of

Agriculture, Lorestan University, Khorramabad, Iran

2 Laboratory of Quality and Safety of Agricultural Products,

Landscape and Environment, Department of Agriculture,

School of Agricultural Sciences, Hellenic Mediterranean

University, Estavromenos, 71004, Heraklion, Greece

* Corresponding author; E-mail: rezaeinejad.h@lu.ac.ir

\section{SUPPLEMENTAL INFORMATION}
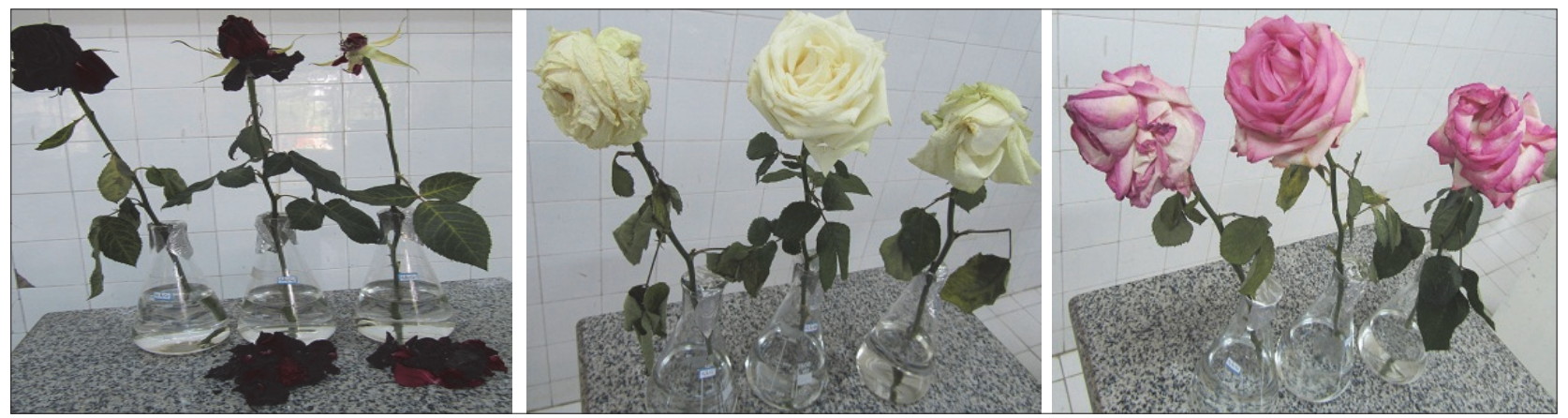

SUPPLEMENTAL INFORMATION - FiguRE S1. Cut flower representative images of three rose cultivars [left panel, 'Samurai'; middle panel, 'Avalanche'; right panel, 'Sorbet'] placed for $12 \mathrm{~d}$ at different vase solution types [tap water (left), deionized water (middle), Van Meeteren solution (right)].
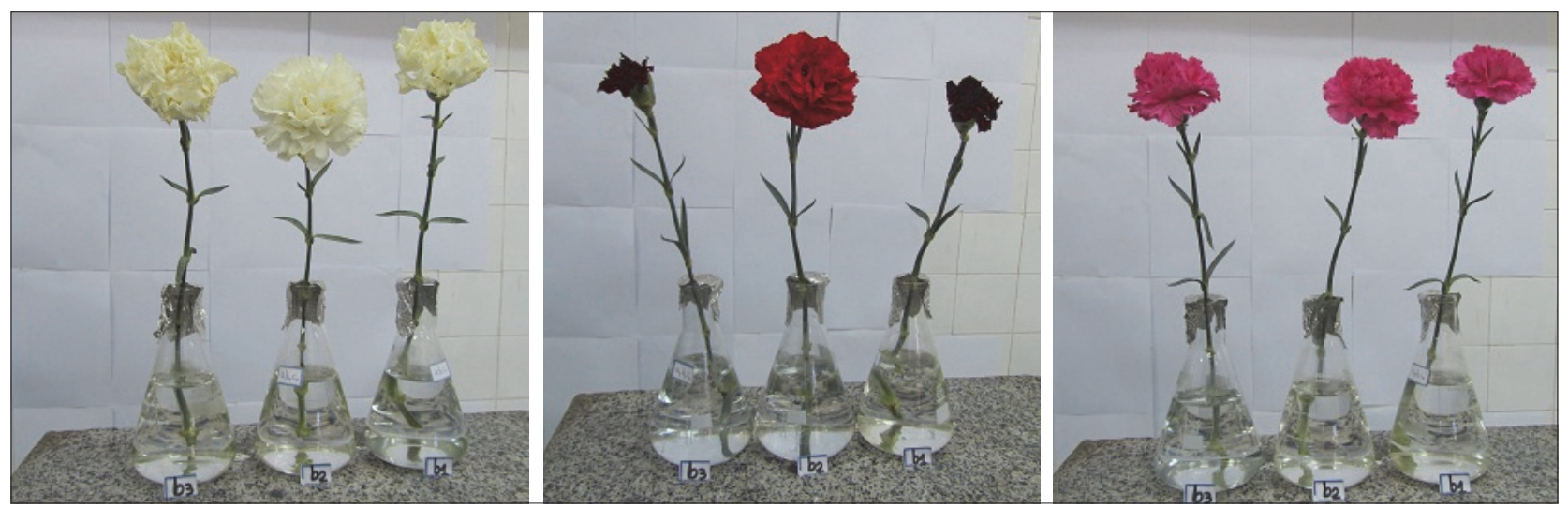

SUPPLEMENTAL INFORMATION - FIGURE S2. Cut flower representative images of three carnation cultivars [left panel, 'White Liberty'; middle panel, 'Grand Slam'; right panel, 'Kirsi'] placed for $11 \mathrm{~d}$ at different vase solution types [tap water (left), deionized water (middle), Van Meeteren solution (right)]. 


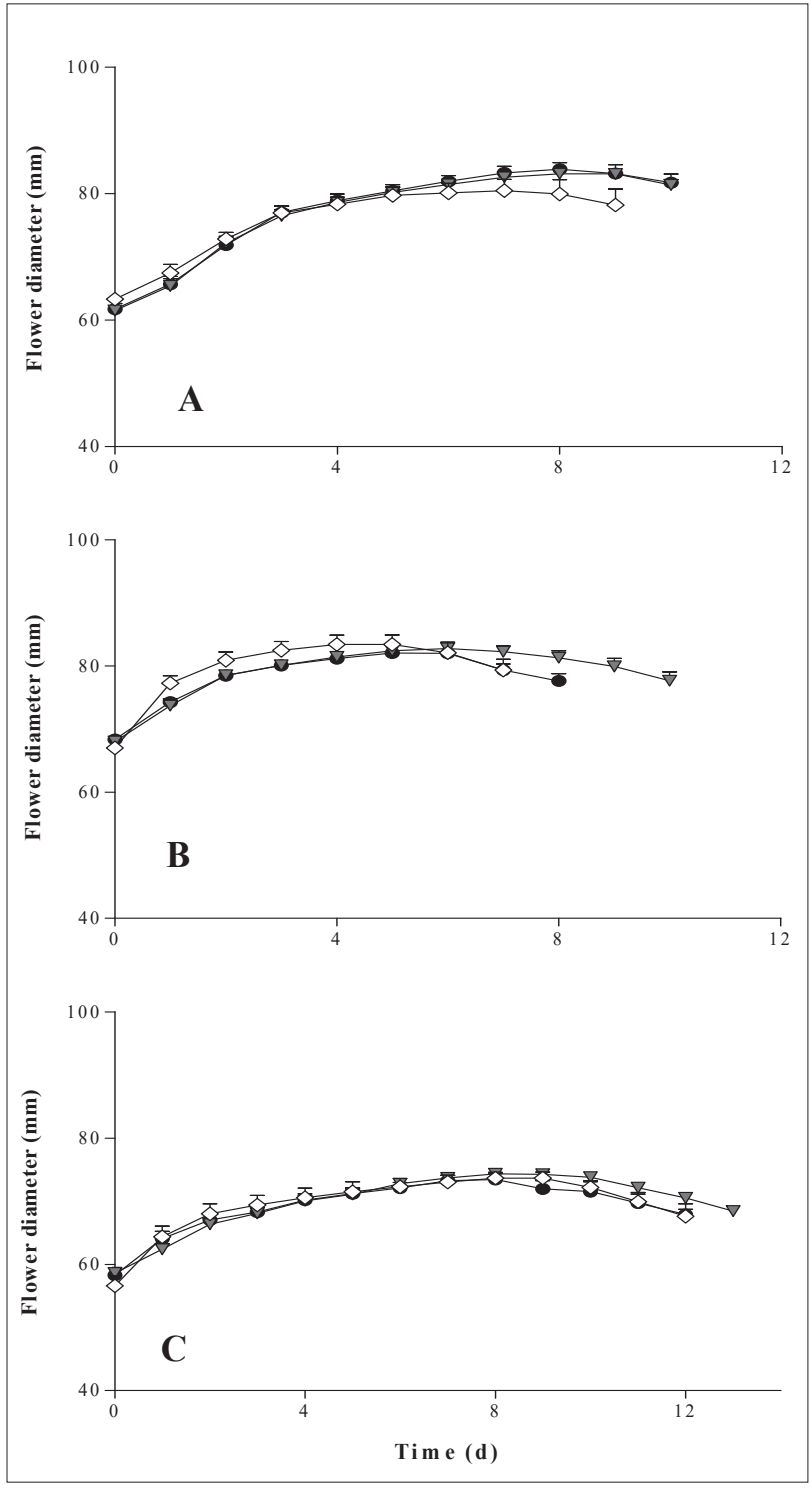

SUPPLEMENTAL INFORMATION - FiguRE S3. Flower bud diameter during vase life as a function of vase solution type [tap water (open symbols), deionized water (grey symbols), Van Meeteren solution (black symbols)] in three cut carnation cultivars (A, 'White Liberty'; B, 'Grand Slam'; $\mathrm{C}$, 'Kirsi'). The maximum diameter together with the diameter perpendicularly to that one were assessed, and these two values were further averaged. Values are the mean of 12 cut flowers \pm sem. When the sem bars are not visible, the sem is smaller than the symbol.
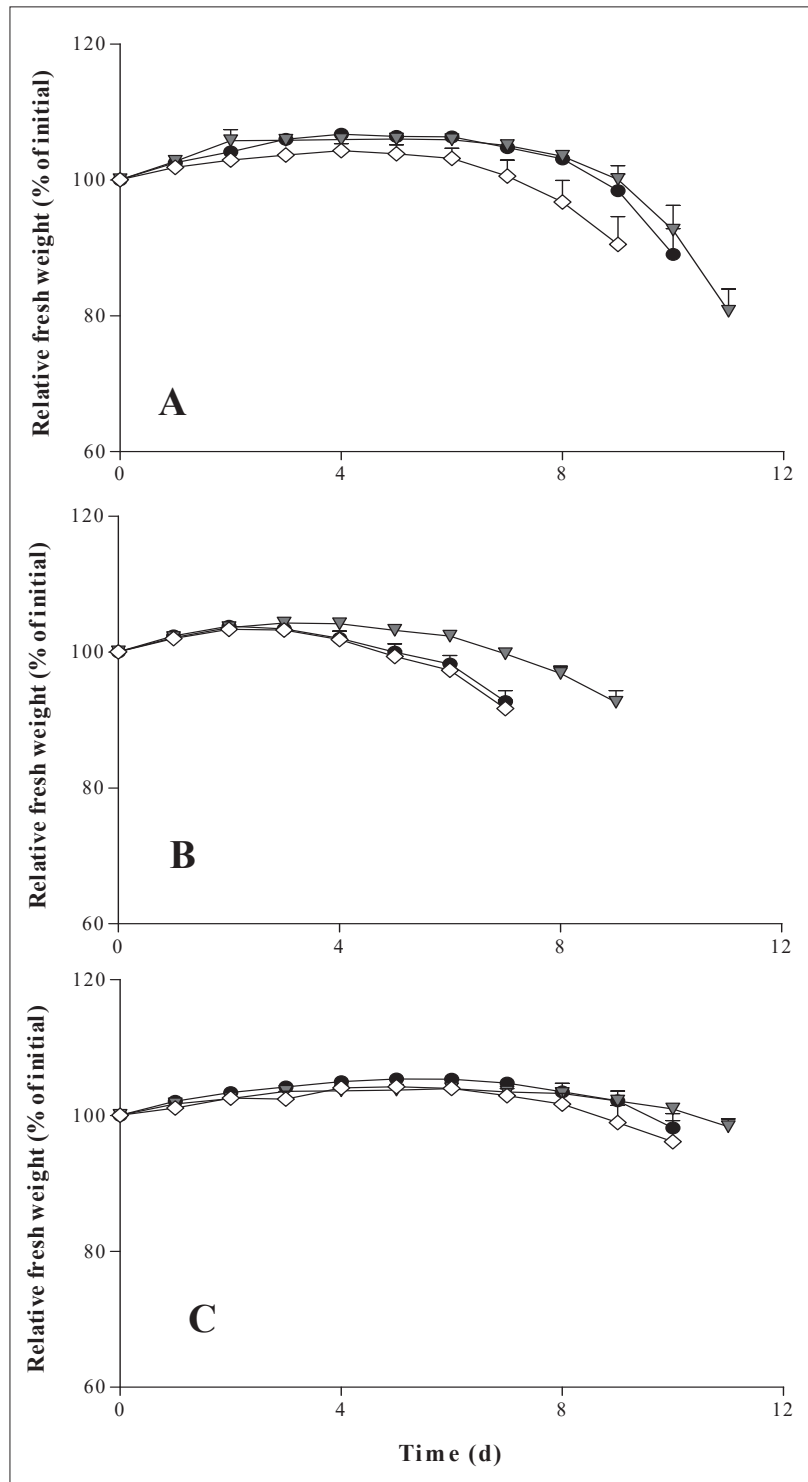

SUPPLEMENTAL INFORMATION - FIGURE S4. Relative fresh weight during vase life as a function of vase solution type [tap water (open symbols), deionized water (grey symbols), Van Meeteren solution (black symbols)] in three cut carnation cultivars (A, 'White Liberty'; B, 'Grand Slam'; C, 'Kirsi'). Cut flowers were of similar weight and wellhydrated. The fresh weight of each flowering stem was expressed relative to its initial weight. Values are the mean of 12 cut flowers \pm sem. When the sem bars are not visible, the sem is smaller than the symbol. 


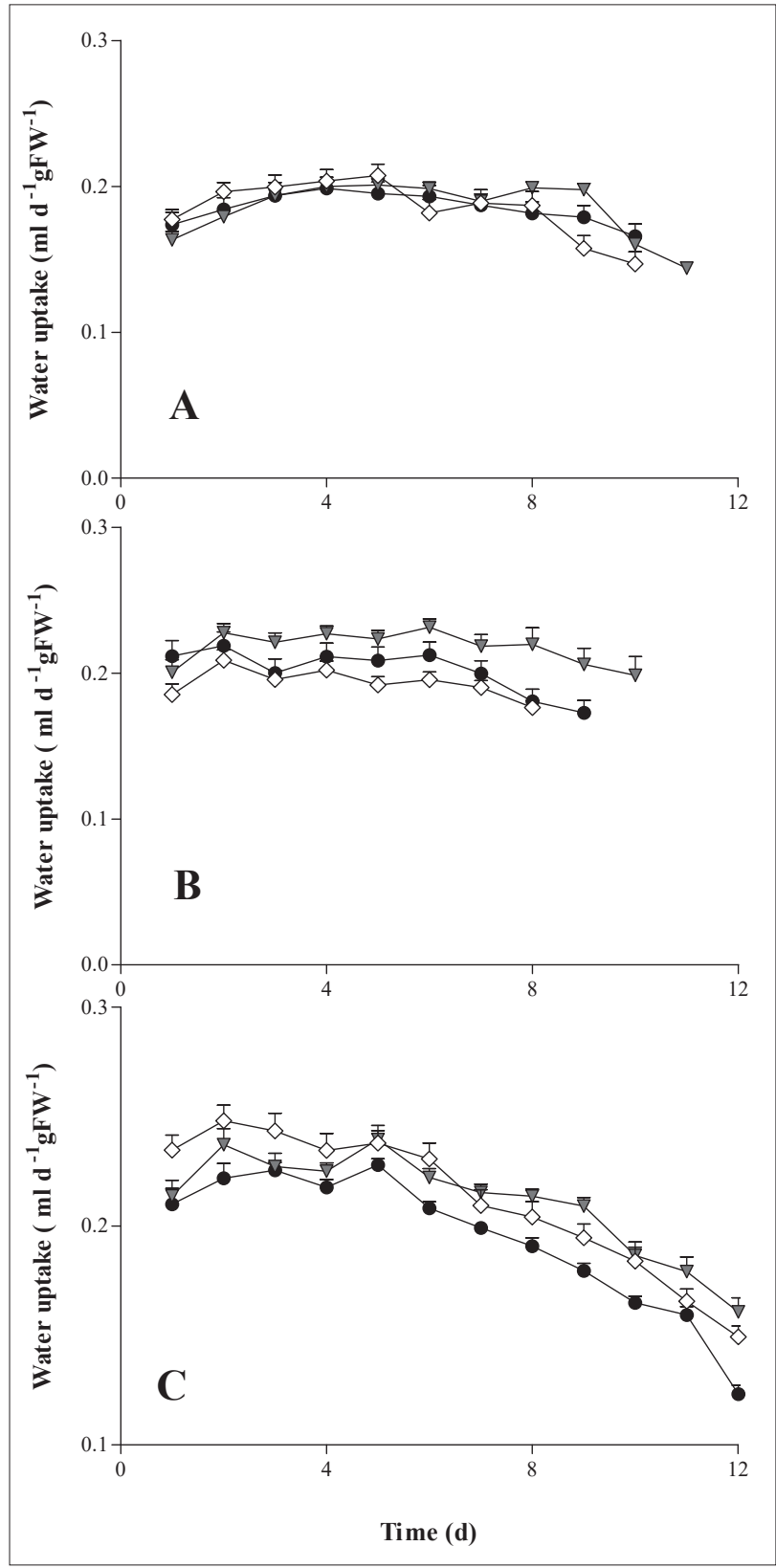

SUPPlemental Information - Figure S5. Water uptake rate during vase life as a function of vase solution type [tap water (open symbols), deionized water (grey symbols), Van Meeteren solution (black symbols)] in three cut carnation cultivars (A, 'White Liberty'; B, 'Grand slam'; C, 'Kirsi'). The water uptake was expressed per unit of time and cut flower fresh weight (FW). Values are the mean of 12 cut flowers \pm sem. When the sem bars are not visible, the sem is smaller than the symbol.

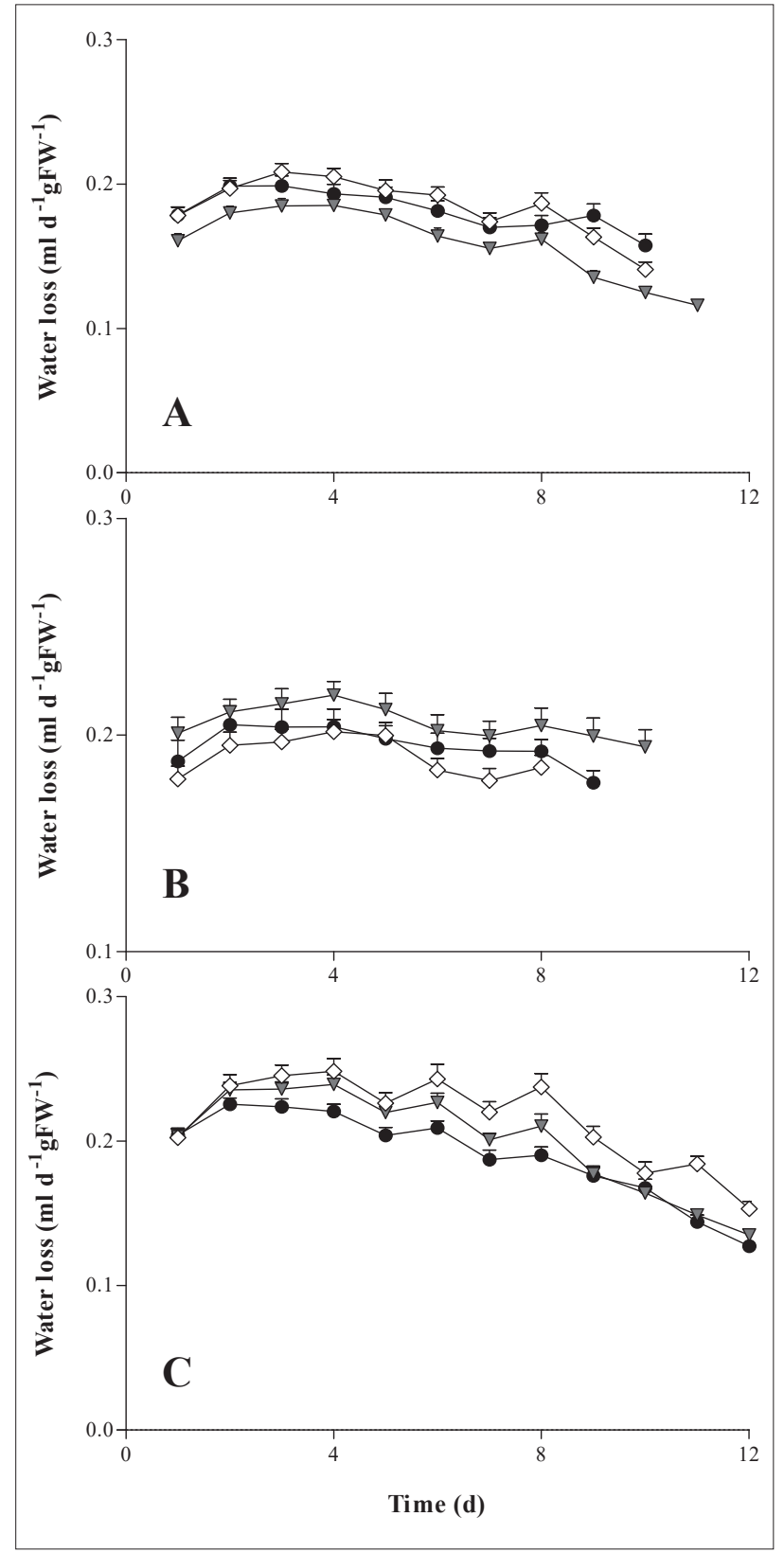

SUPPLEMENTAL INFORMATION - FiguRE S6. Water loss rate during vase life as a function of vase solution type [tap water (open symbols), deionized water (grey symbols), Van Meeteren solution (black symbols)] in three cut carnation cultivars (A, 'White Liberty'; B, 'Grand Slam'; C, 'Kirsi'). The water loss was expressed per unit of time and cut flower fresh weight (FW). Values are the mean of 12 cut flowers \pm sem. When the sem bars are not visible, the sem is smaller than the symbol. 